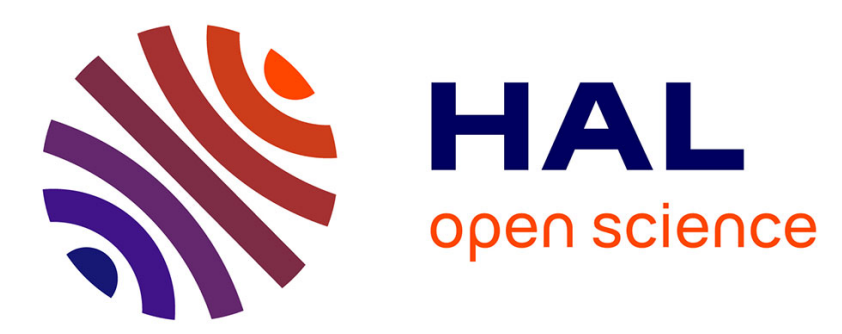

\title{
Impact of Two Microphysical Schemes upon Gas Scavenging and Deposition in a Mesoscale Meteorological Model
}

Nadine Chaumerliac, Evelyne Richard, Robert Rosset, Everett Nickerson

\section{- To cite this version:}

Nadine Chaumerliac, Evelyne Richard, Robert Rosset, Everett Nickerson. Impact of Two Microphysical Schemes upon Gas Scavenging and Deposition in a Mesoscale Meteorological Model. Journal of Applied Meteorology, 1991, 30 (1), pp.88 - 97. 10.1175/1520-0450(1991)0302.0.CO;2 . hal-01819443

\author{
HAL Id: hal-01819443 \\ https://hal.uca.fr/hal-01819443
}

Submitted on 2 Feb 2021

HAL is a multi-disciplinary open access archive for the deposit and dissemination of scientific research documents, whether they are published or not. The documents may come from teaching and research institutions in France or abroad, or from public or private research centers.
L'archive ouverte pluridisciplinaire HAL, est destinée au dépôt et à la diffusion de documents scientifiques de niveau recherche, publiés ou non, émanant des établissements d'enseignement et de recherche français ou étrangers, des laboratoires publics ou privés. 


\title{
Impact of Two Microphysical Schemes upon Gas Scavenging and Deposition in a Mesoscale Meteorological Model
}

\author{
Nadine Chaumerliac, Evelyne RichaRd aNd Robert Rosset \\ LAMP/OPGC, Clermont-Ferrand, France \\ EVERETT C. NICKERSON
}

NOAA, Forecast Systems Laboratory, Boulder, Colorado

(Manuscript received 13 September 1989, in final form 3 July 1990)

\begin{abstract}
Two widely used microphysical schemes are compared to evaluate their possible impact on wet deposition mechanisms. They are based upon different spectral distributions for raindrops (Marshall-Palmer and lognormal distributions) and use different formulations for the autoconversion and evaporation processes, as well as for the fall velocity of raindrops. A comparative study of these two schemes is carried out for a two-dimensional mountain wave simulation in a mesoscale meteorological model. Differences in the spatial and temporal evolution of microphysical fields are investigated. The two schemes are compared for simple chemical scenarios: gas dissolution in cloud and rain, gas scavenging by raindrops, and wet deposition. Results contrast the differing behavior of the two schemes in describing processes such as the direct scavenging of gases by raindrops and the release of chemical species back into the atmosphere because of below-cloud evaporation of rain.
\end{abstract}

\section{Introduction}

Acid deposition results from closely coupled and complex interactions between microphysical, dynamical, and chemical processes. For example, coalescence mechanisms determine the partitioning of chemical soluble species and consequently the partitioning of acidity between cloud and rain. The dependency on drop sizes of dissolution and mass transfer processes establishes the need for a thorough treatment of microphysical processes. Recent theoretical predictions from a cloud model (Flossmann and Pruppacher 1988) and experimental observations (Noone et al. 1988) have suggested that rainwater composition is drop-size dependent. This drop-size dependency cannot always be incorporated into a model. One can use the wellknown Kessler scheme (Niewiadomski 1986), which can be included in a mesoscale meteorological model but excludes drop-size dependent chemistry, or one can rely on a sophisticated cloud model (Flossmann and Pruppacher 1988) that addresses the question of drop-size dependent chemistry but is compatible only with simplified dynamics. A microphysical parameterization derived from the stochastic coalescence equation of a cloud model has been proposed (Berry and Reinhardt 1974a, 1974b) and implemented in a mesoscale meteorological model (Nickerson et al.

Corresponding author address: Dr. Nadine Chaumerliac, LAMP/ OPGC, 12 Avenue des Landais, 6300 Clermont Ferrand, France.
1986). This formulation, which is between the two extremes above, offers a greater possibility of simulating the relevant microphysical processes than that of Kessler.

Richard and Chaumerliac (1989) gave the results of a systematic comparison of those two microphysical schemes (Kessler 1969; Berry and Reinhardt 1974a, 1974b) for an idealized case of a moist mountain wave. Results from that comparison are given in Richard and Chaumerliac (1989). One of the conclusions of that paper was that the major differences found in raindrop size distributions as well as in the formulation of some microphysical processes should lead to divergent results between the two schemes when considering wet chemistry problems. The aim of the present study was to examine the impact of those microphysical differences on the wet deposition of a soluble, nonreactive gas. Sensitivity tests with various solubilities as well as direct scavenging by raindrops are studied for this orographic situation using two different microphysical schemes. This study considers only warm-cloud processes.

\section{Microphysical schemes}

The main features of the Kessler (1969) parameterization and that of Berry and Reinhardt (1974a,b) are briefly summarized. In both cases, liquid water is partitioned into cloud water and rainwater. The cloudwater mixing ratio $q_{c w}$ is diagnosed from the prognostic variable $q$, which is the sum of the water-vapor mixing 
ratio $q_{v}$ and the cloud-water mixing ratio $q_{c w}$. When supersaturation occurs, $q_{v}$ is set equal to the saturated vapor mixing ratio $q_{v s}$, and the excess vapor is converted into cloud water. For rainwater, the mixing ratio is predicted in both schemes, but another predictive equation is added for the total number concentration in the scheme of Berry and Reinhardt. This allows for self-collection and partial evaporation of raindrops.

The Kessler parameterization uses a Marshall-Palmer distribution for raindrops, whereas a lognormal function is assumed for Berry and Reinhardt. Both schemes include the processes of autoconversion, accretion, sedimentation, and evaporation. However, selfcollection is considered only in the Berry and Reinhardt parameterization.

Formulations of the various microphysical rates and the differences between them are given in detail in Richard and Chaumerliac (1989). In this paper, only the autoconversion rates are given as an example.

For Kessler, the autoconversion rate relative to the mixing ratio is written as

$$
A U_{K}(Q)= \begin{cases}k_{1}\left(\rho_{a} q_{c w}-a\right), & \text { if } \rho_{a} q_{c w}>a ; \\ 0, & \text { if not, }\end{cases}
$$

where $a$ designates the threshold value for autoconversion below which cloud conversion does not occur. Here $a=0.5 \mathrm{~g} \mathrm{~m}^{-3}, \rho_{a}$ is the air density, and $k_{1}$ is the Kessler autoconversion coefficient commonly set equal to $10^{-3} \mathrm{~s}^{-1}$.

For Berry and Reinhardt, two rates must be considered for the autoconversion: one relative to the mixing ratio and the other relative to the total number concentration. These are written respectively as

$$
\begin{gathered}
A U_{B R}(Q)=\alpha\left(\overline{D_{c w}}, \sigma_{c}\right)\left(\rho_{a} q_{c w}^{2}\right) \\
A U_{B R}(N)=3.5 \times 10^{9} \alpha\left(\overline{D_{c w}}, \sigma_{c}\right)\left(\rho_{a} q_{c w}\right)^{2} .
\end{gathered}
$$

The coefficient $\alpha$ depends on cloud spectrum features, $\overline{D_{c w}}$ is the cloud-droplet mean volume diameter, and $\sigma_{c}$ is the standard geometric deviation for the cloud lognormal spectrum. In this paper, the coefficient $\alpha$ is set equal to 0.15 . Also set are $\overline{D_{c w}}=27.5 \mu \mathrm{m}$ and $\sigma_{c}$ $=0.2775$, which are typical values for a maritime cloud spectrum (Berry and Reinhardt 1973). Richard and Chaumerliac (1989) provide other values, and it has been shown that $\alpha=0.15$ results in comparable cloudwater mixing ratios for the two schemes in a mountain wave scenario. These comparable conditions are retained here to permit a closer comparison between wet deposition results obtained with the two microphysical schemes.

\section{The chemical scheme}

A soluble, nonreactive gas is considered in the model and is described by three predictive equations that represent it in three forms: its gaseous phase, its dissolved form in cloud water, and its dissolved form in rain- water. Three phase concentrations of the species $X$ are defined: a gaseous one, a concentration in cloud water, and a concentration in rainwater, denoted respectively as $X_{\alpha}, X_{c}$, and $X_{r}$.

The time rate of change of each concentration for a given soluble species is obtained from the following set of equations:

$$
\begin{gathered}
d X_{a} / d t=-S_{d i s}-S_{\text {scav }} \\
d X_{c} / d t=S_{d i s}-S_{a c c}-S_{a u t} \\
d X_{r} / d t=S_{a c c}+S_{a u t}+S_{\text {sed }}+S_{\text {scav }},
\end{gathered}
$$

where $S$ stands for the various sources and sinks of the concentrations. The subscript "aut" refers to autoconversion of cloud droplets into raindrops and " $a c c$ " to accretion of cloud droplets by raindrops. The subscript "sed" refers to sedimentation. The subscripts "dis" and "scav" designate respectively the dissolution in aqueous phase of $X$ and the scavenging from gas phase to rainwater through mass transfer. The left-hand sides of Eqs. (4)-(6) include transport and friction. The detailed expressions for all the sources and sinks for the various phase concentrations are given in Chaumerliac et al. (1989), except for the rate of dissolution of the gaseous species into cloud water, which was treated slightly different.

In the present paper, two distinct predictive equations are considered for the concentration of the species in the air and in the cloud environment, respectively, which was not the case in Chaumerliac et al. (1989). This greater degree of freedom implies that a dissolution rate of the gaseous species into cloud water must also be considered and is expressed as

$$
X_{\text {dis }}=\left.X_{a} H_{e f f} R T \frac{\partial q_{c w}}{\partial t}\right|_{\text {cond }},
$$

where $\partial q_{c w} /\left.\partial t\right|_{\text {cond }}$ is the condensation rate and $H_{e f f}$ is the effective solubility in moles per atmosphere for $X$ in aqueous phase. In the sensitivity studies that follow, two types of species are considered. One is a species with a low effective solubility (sulfur dioxide), and the other corresponds to a very soluble species (hydrogen peroxide). However, to compare the impact of the two rain parameterizations on wet deposition processes, one assumes that the species (which are taken to be either $\mathrm{SO}_{2}$ or $\mathrm{H}_{2} \mathrm{O}_{2}$ ) are nonreactive. It should also be noted that gas scavenging by water drops is calculated by the diffusion-controlled kinetic formula, as given in Iribarne and Cho (1989):

$$
F=k_{g}\left(C-C_{e q}\right),
$$

where $F$ is the density of flux of gas toward the drop, $C$ is the gas phase concentration, and $C_{e q}$ is the value in equilibrium with the aqueous concentration in the liquid.

The coefficient $k_{g}=f D_{g} / r$ (where $D_{g}$ is the diffusivity in the gas phase and $r$ is the drop radius) contains a correction factor $f$ that represents the mass transfer 
enhancement produced by the relative motion of the drop and the air and by the drag-induced internal circulation. As discussed in Walcek et al. (1984),

$$
\begin{array}{lll}
\text { for } & r<500 \mu \mathrm{m}, & f=1 \\
\text { for } & 500<r<900 \mu \mathrm{m}, & f=2.5 \\
\text { and for } & r>900 \mu \mathrm{m}, & f=20 .
\end{array}
$$

Section 4 describes the results from a series of numerical experiments that successively combine the chemical scheme described above with the microphysical parameterizations from Kessler (1969) and Berry and Reinhardt (1974a,b) in a meteorological setting corresponding to two-dimensional orographic flow.

\section{Model results}

The meteorological scenario is defined as in previous papers (Richard and Chaumerliac 1989; Chaumerliac et al. 1987) and consists of a two-layer atmosphere over an idealized bell-shaped mountain. The initial horizontal wind speed is a uniform $20 \mathrm{~m} \mathrm{~s}^{-1}$, and a relative humidity of $80 \%$ is assumed below $3 \mathrm{~km}$.

The gas variable is initialized with uniform concentrations in the vertical, initially taken equal to $1 \mathrm{ppb}$ to facilitate the interpretation of the sensitivity tests.

Simulations were performed with a two-dimensional version of the model (Nickerson et al. 1986) over a horizontal domain of $430 \mathrm{~km}$, using a horizontal grid length of $10 \mathrm{~km}$. The calculations were carried out to $6 \mathrm{~h}$ using a time step of $10 \mathrm{~s}$.

Before discussing the wet chemistry, a recapitulation of the results from both microphysical parameterizations in the orographic rain situation is presented. In Fig. 1, vertical cross sections of cloud-water mixing ratio, rainwater mixing ratio, and precipitation rate are given for Kessler (1969) and Berry and Reinhardt (1974.a,b). As previously mentioned, the choice of the autoconversion coefficient in the Berry and Reinhardt scheme leads to cloud-water mixing ratios comparable to those obtained with the Kessler scheme. The precipitation rates are also comparable in intensity but differ slightly in their spatial extent. In contrast, the corresponding rainwater mixing ratios are quite different. It was shown in Richard and Chaumerliac (1989) that the difference occurs because rainwater mass is carried by much larger raindrops in the Kessler case. 'Those larger raindrops precipitate with larger fall velocities than in the case of Berry and Reinhardt, leading to much faster depletion of the rainwater mixing ratio in the Kessler scheme. A good illustration of the differing behavior of the two schemes is also provided in Fig. 2, which shows mass density functions for Kessler and Berry and Reinhardt for various model grid points in the vicinity of the mountain top. In all cases, the Kessler mass density functions are centered over larger drop diameters.

Another effect related to raindrop size is the downwind spreading of the precipitation zone in the case of Berry and Reinhardt. The smaller Berry and Reinhardt raindrops are more sensitive to wind drift effects. It can already be inferred that the inherent differences between each microphysical scheme should lead to differing results for the gas scavenging and deposition processes.

To study the impact of those differences upon the chemical processes, a series of numerical experiments was performed: in the first experiment, scavenging of a very soluble gas is considered $\left(H_{e f f}==10^{5} \mathrm{M} \mathrm{atm}^{-1}\right)$; in the second experiment Henry's law equilibrium is assumed for the raindrops for the same gas; and the last experiment consists of the transport and scavenging of a less soluble gas $\left(H_{e f f}=10^{3} \mathrm{M}^{\mathrm{atm}}{ }^{-1}\right)$. In all cases, the gas is assumed to be nonreactive.

Results from the first experiment are shown in Fig. 3 with the partitioning of a highly soluble gas between air, cloud and rain. Vertical cross sections of gaseous and aqueous concentrations in nanomole per liter of air are plotted after $6 \mathrm{~h}$ of simulation time. For airborne concentrations, the depletion of gas due to gas uptake by cloud and rain looks quite different for the two microphysical schemes on the downwind side. The gas is more efficiently scavenged on the downwind side of the mountain in the case of the Berry and Reinhardt parameterization. This is because the rainwater mixing ratio in the Berry and Reinhardt scheme is 3-5 times larger than that of Kessler (see Fig. 1). Also, the smaller raindrops of the Berry and Reinhardt case are more sensitive to advection and consequently have a longer residence time in the atmosphere, allowing for more efficient scavenging of the gas on the downwind side of the mountain.

Looking now at the contours for gas scavenged by cloud, one finds three cells of maximum concentration in the Kessler case, whereas there is only one cell for the Berry and Reinhardt scheme. This can be related to the threshold behavior in the autoconversion process in the Kessler case, which results in an accumulation of gas in the cloud phase before conversion to rain. For the same reason, we observe a distortion of the contours on the downwind side in the Kessler case because dissolved gas in cloud can be advected below the autoconversion threshold. However, the amounts of aqueous species in the cloud are about the same with the two parameterizations, reflecting the behavior already noticed in the cloud-water fields.

For rainwater species, differences between the two microphysical schemes are much stronger than is the case for airborne and cloudborne species. Aqueous concentrations in rainwater are about three times greater in the Berry and Reinhardt simulation than in the Kessler one. This reflects the rainwater fields, but it also shows a greater absorption of gases upwind from 
KESSLER

\section{BERRY-REINHARDT}
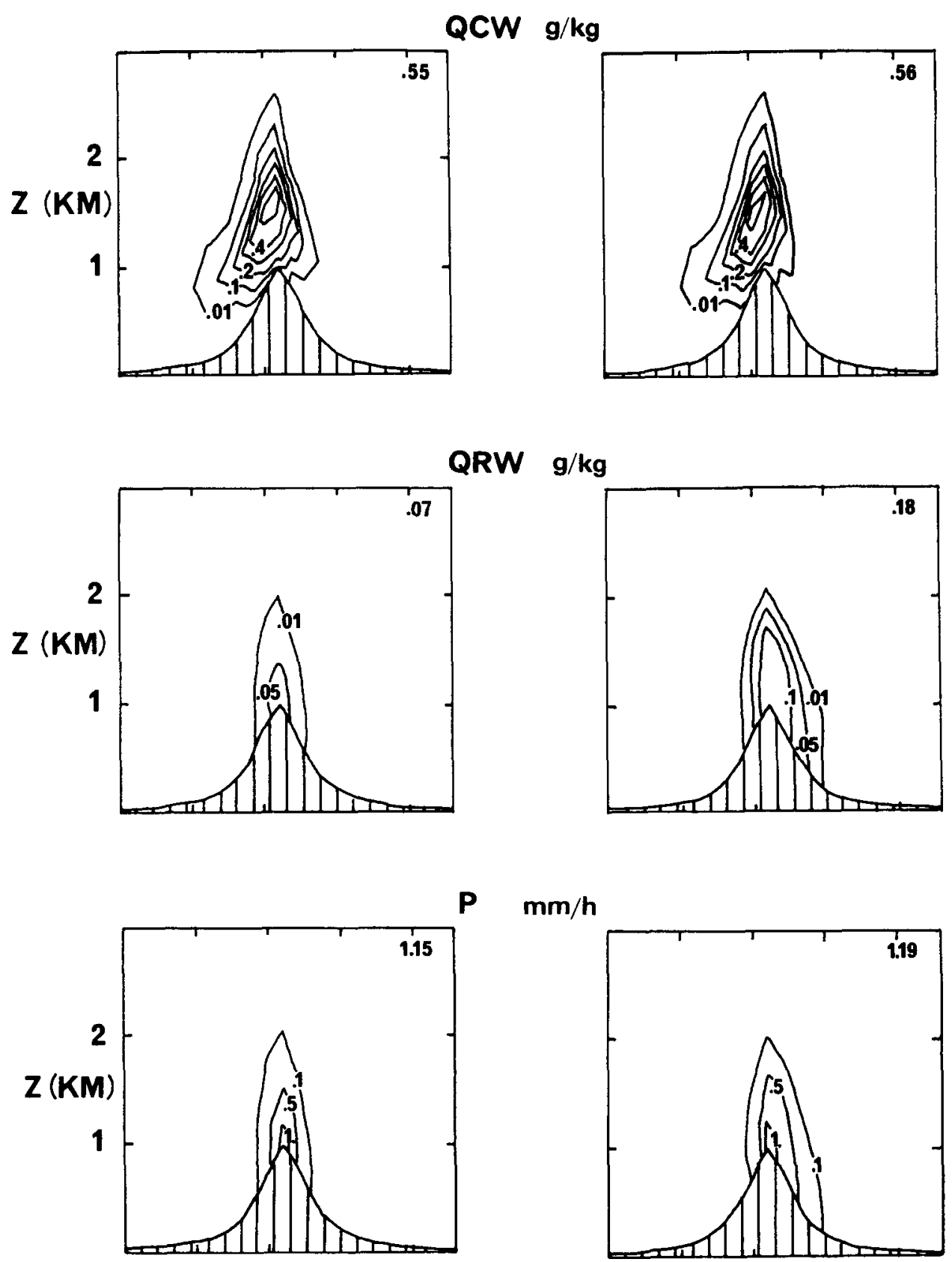

$\mathrm{mm} / \mathrm{h}$

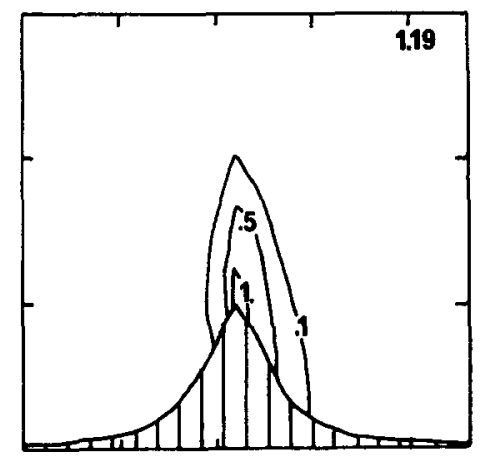

$50 \mathrm{KM}$

FIG. 1. Vertical cross sections of cloud-water mixing ratio $q_{c w}$, rainwater mixing ratio $q_{r w}$, and precipitation rate $P$, for Kessler (1969) and Berry and Reinhardt (1974a,b). Maximum values are indicated in the upper right corner of each figure.

the mountain top, probably because rainwater is carried by the smaller raindrops of the Berry and Reinhardt case. These differences in the condensation zone as well as the behavior already noticed in the airborne concentration fields in the evaporation zone lead us to believe that direct scavenging of gases by raindrops is the process responsible for such a pattern. Other processes leading to rainborne species production or destruction are derived from microphysical processes through proportionality relationships and cannot result 


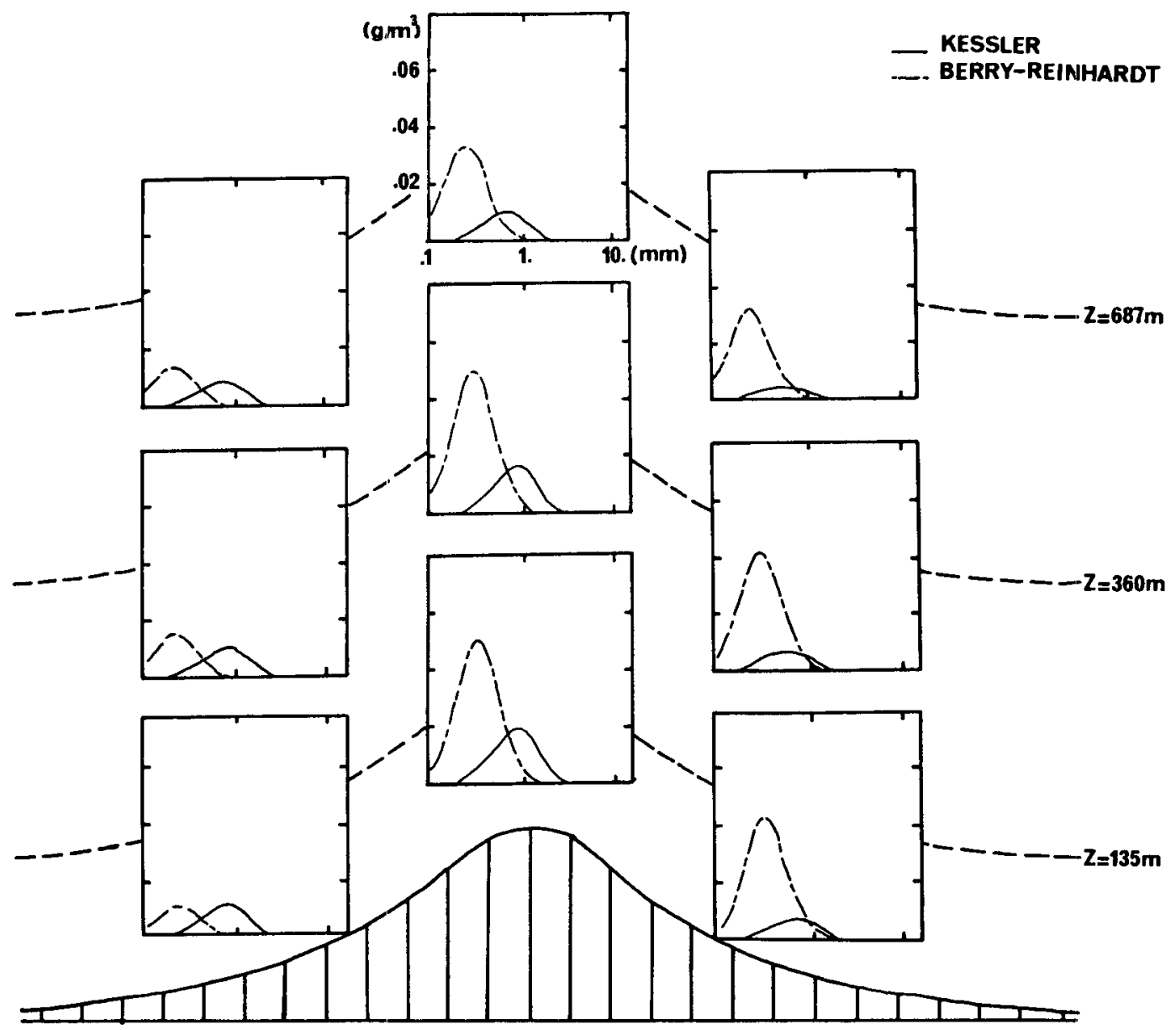

FIG. 2. Mass density functions for raindrops with Kessler ( 1969) and Berry and Reinhardt (1974a,b) droplet spectra for three grid points located at mountain top and upwind and downwind from mountain top for three vertical levels in the model.

in nonlinearities between the microphysical rainwater fields and the corresponding chemical fields.

To see the impact of direct scavenging of gases by raindrops on the source or sink of aqueous species, a sensitivity test was performed in which we assumed Henry's law equilibrium for gas dissolution in raindrops. Results are presented in Fig. 4 in the same format as in Fig. 3. When Henry's law equilibrium is maintained in the rain formation processes as for the cloud water, then the amount of trace gases transferred from the cloud water to the rainwater is about one-thirdone-half that of cloud-water field. Mass transfer limitation reduces the gas absorption by about a factor of 2 , as seen on the rainborne species' fields, and decreases the concentration effect when raindrops evaporate below the cloud, as shown on airborne species' fields on the downwind side from the mountain top. The main contrast between the two microphysical schemes is in a greater desorption zone of gases downwind from mountain top in Berry and Reinhardt case when equilibrium is assumed. The differences may be attributed to a more efficient total evaporation in the case of the smaller Berry and Reinhardt raindrops.

A summary of the principal results for the entire series of numerical experiments is presented in Fig. 5, which shows deposition rates for the two microphysical parameterizations and the three sensitivity tests. The first two sets of figures display deposition rates obtained with mass transfer limitations included for a very soluble gas and a less soluble one. Again, observe the downwind spreading of the deposition zone in the case of Berry and Reinhardt, which should be related to the corresponding effect already noted in the precipitation rate. Lowering the solubility has the effect of reducing the deposition rate for both microphysical schemes. In the case of Berry and Reinhardt, the maximum of the deposition rate is displaced slightly downwind from the mountain top and is much more concentrated in the case of the less soluble gas. The drift effect of smaller raindrops in the Berry and Reinhardt case is enhanced here, owing to a longer residence time for the less soluble species. Mass transfer limitation effects are of ma- 
KESSLER
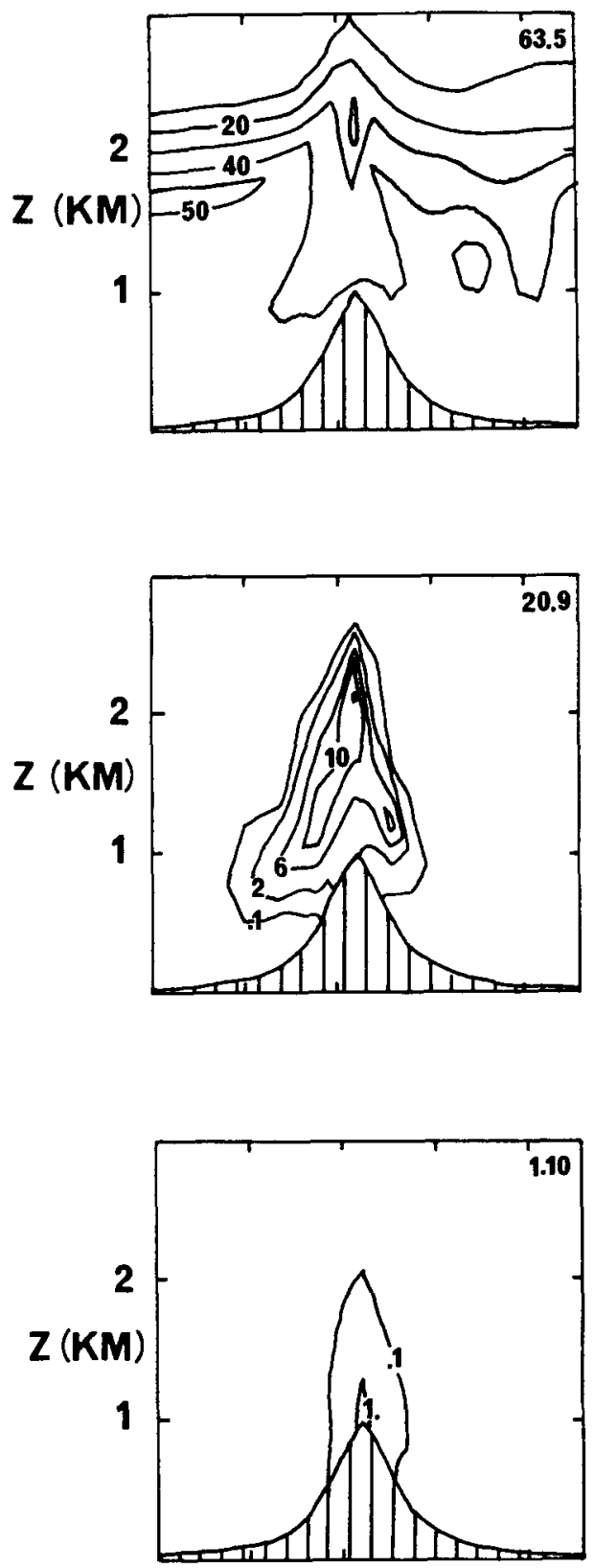

\section{BERRY-REINHARDT}

AIR

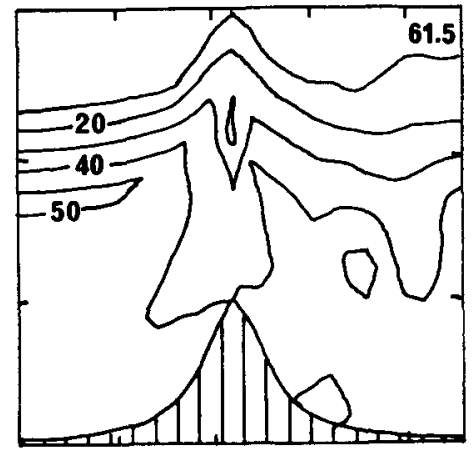

\section{CLOUD}

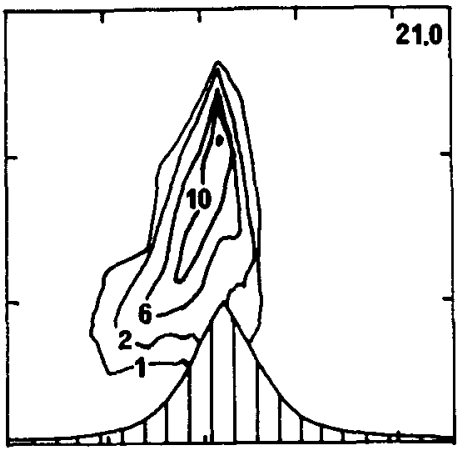

RAIN

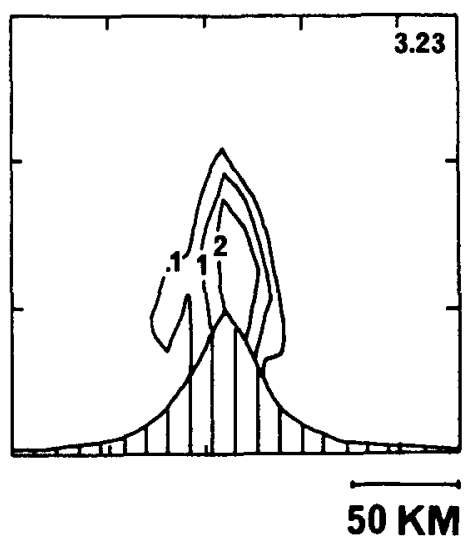

FIG. 3. Vertical cross sections of concentrations for a highly soluble species in air, in cloud, and in rain environments in nanomoles per liter of air.

jor importance, especially with the Berry and Reinhardt scheme: when Henry's law equilibrium is assumed, the deposition rates for the Kessler scheme have about the same order of magnitude while Berry and Reinhardt deposition rates are two times greater than when the mass transfer limitation is considered.
Additional evidence of the relative importance of processes involved in gas scavenging by raindrops is found in Fig. 6, where the temporal evolution of different sources and sinks for rainborne species is shown by 1) microphysical processes such as autoconversion and accretion, 2) evaporation processes, 3 ) dissolution 
KESSLER
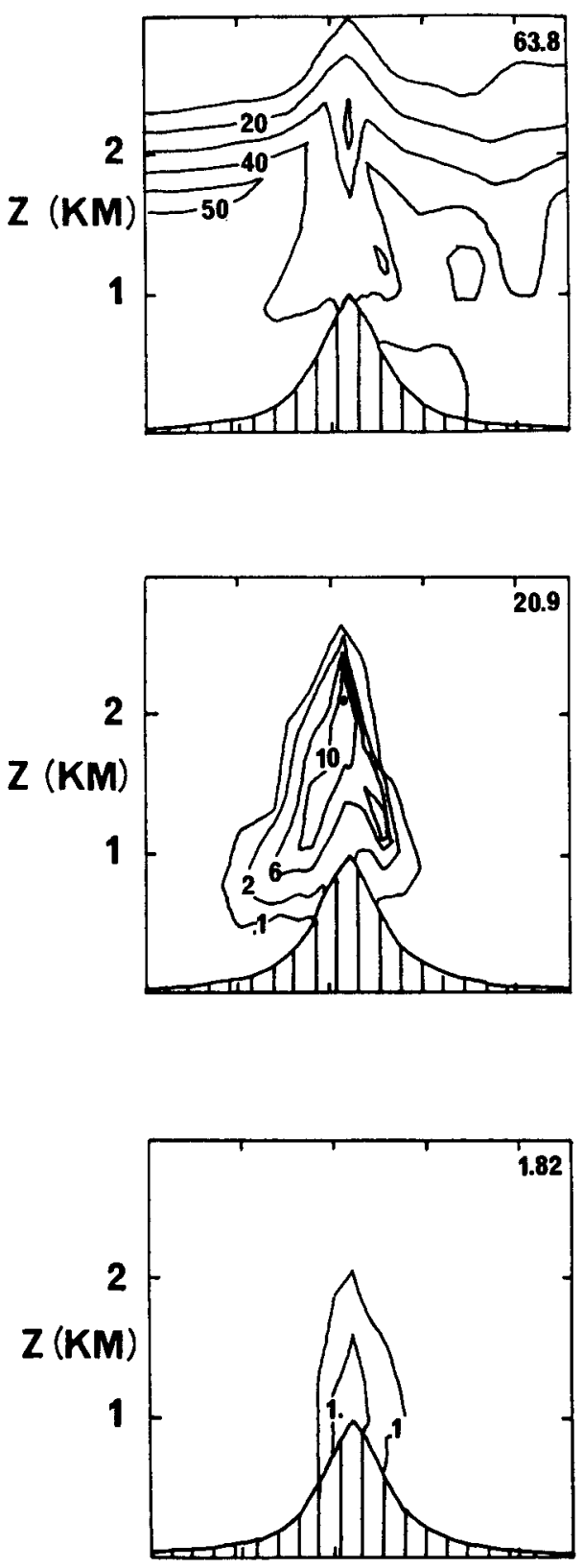

BERRY-REINHARDT

AIR

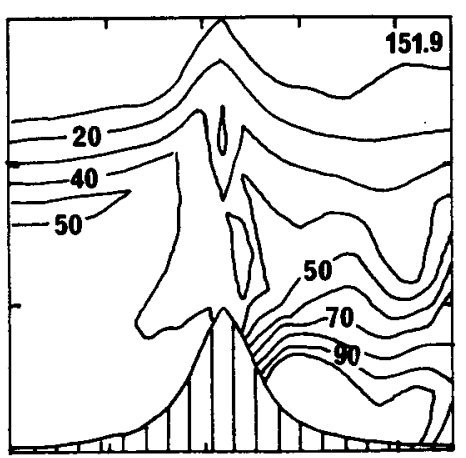

CLOUD

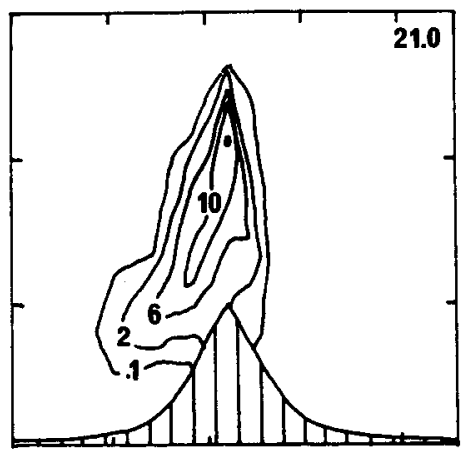

\section{RAIN}

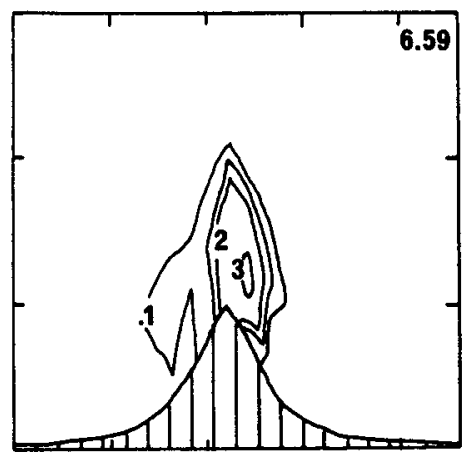

$50 \mathrm{KM}$

Fig. 4. Same as in Fig. 3, but Henry's law equilibrium is assumed for gas dissolution in raindrops.

of gas into raindrops, and 4) sedimentation of raindrops. The budgets were calculated for a period of $2 \mathrm{~h}$ by integrating the expressions representing the individual processes over the entire model domain. For example, the term for the microphysical process is calculated as follows:

$$
\int_{0}^{L_{x}} \int_{0}^{L_{z}}\left(S_{a u t}+S_{a c c}\right) d x d z
$$

where $L_{x}$ and $L_{z}$ are the horizontal and vertical extents, respectively, of the model domain, and $S_{a u t}$ and $S_{a c c}$ are defined in Eq. 6. For a highly soluble species, mi- 
KESSLER
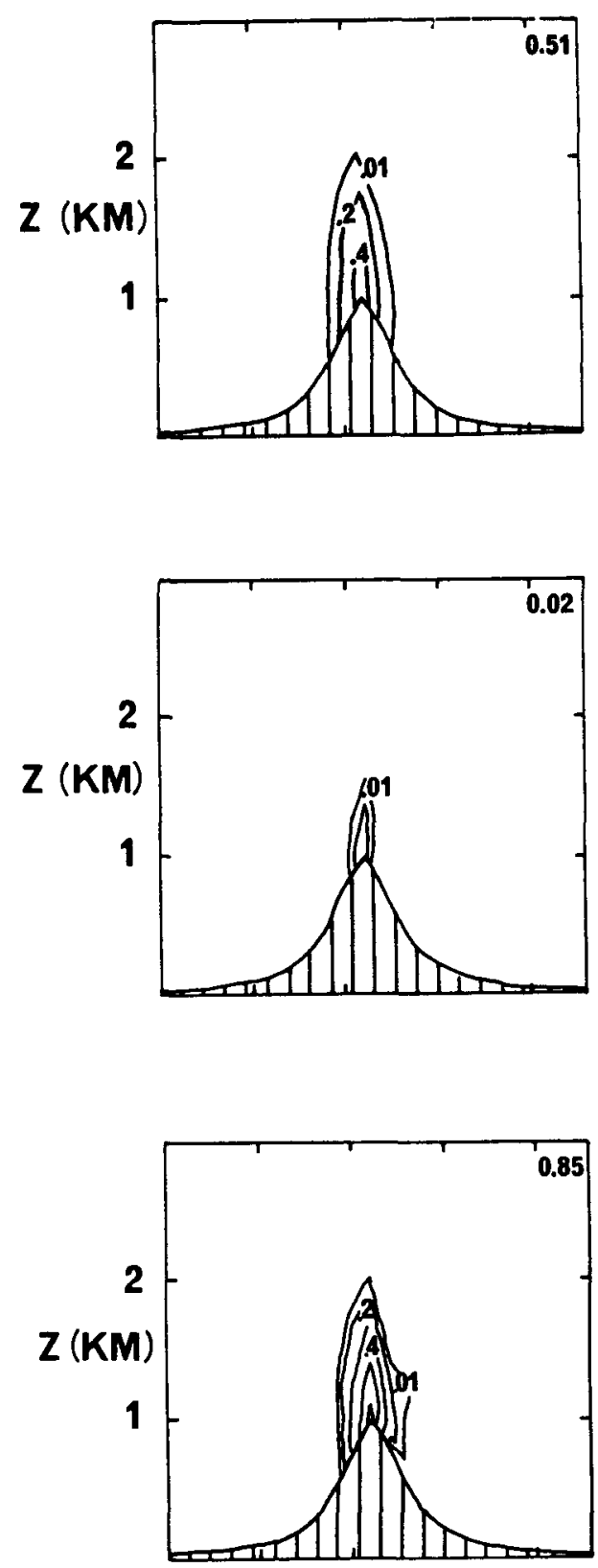

BERRY-REINHARDT

A

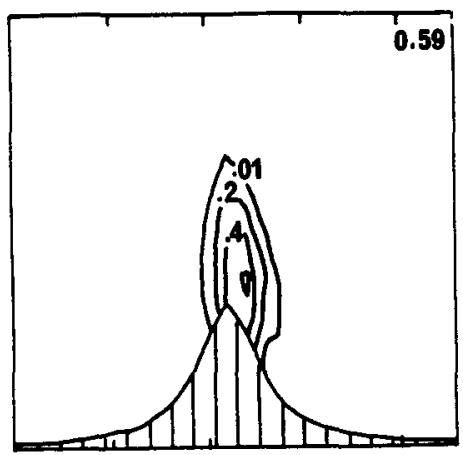

B

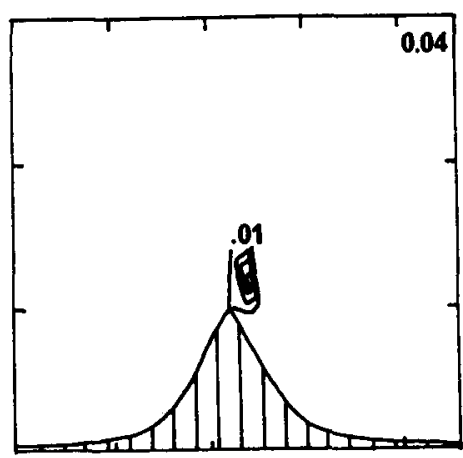

C

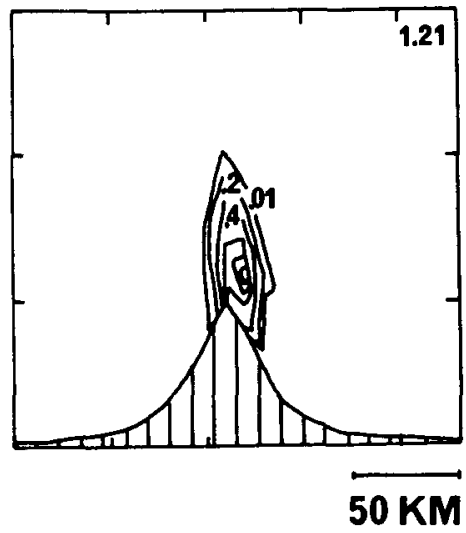

FIG. 5. Vertical cross sections of deposition rates in micrograms per square meter per second for three sensitivity cases. For the first two cases, effects of direct scavenging of gases by raindrops are shown for a highly soluble species and a less soluble one. The third case considers that Henry's law equilibrium is obeyed for the highly soluble gas.

crophysical processes together with evaporation and sedimentation dominate over scavenging effects in both the Kessler and the Berry and Reinhardt cases because the species were already dissolved in the cloud and partly converted into the rain. Because of the autoconversion threshold effects in the Kessler case, gases have more time to dissolve in the cloud, and therefore the microphysical conversion of cloudborne species into 
KESSLER
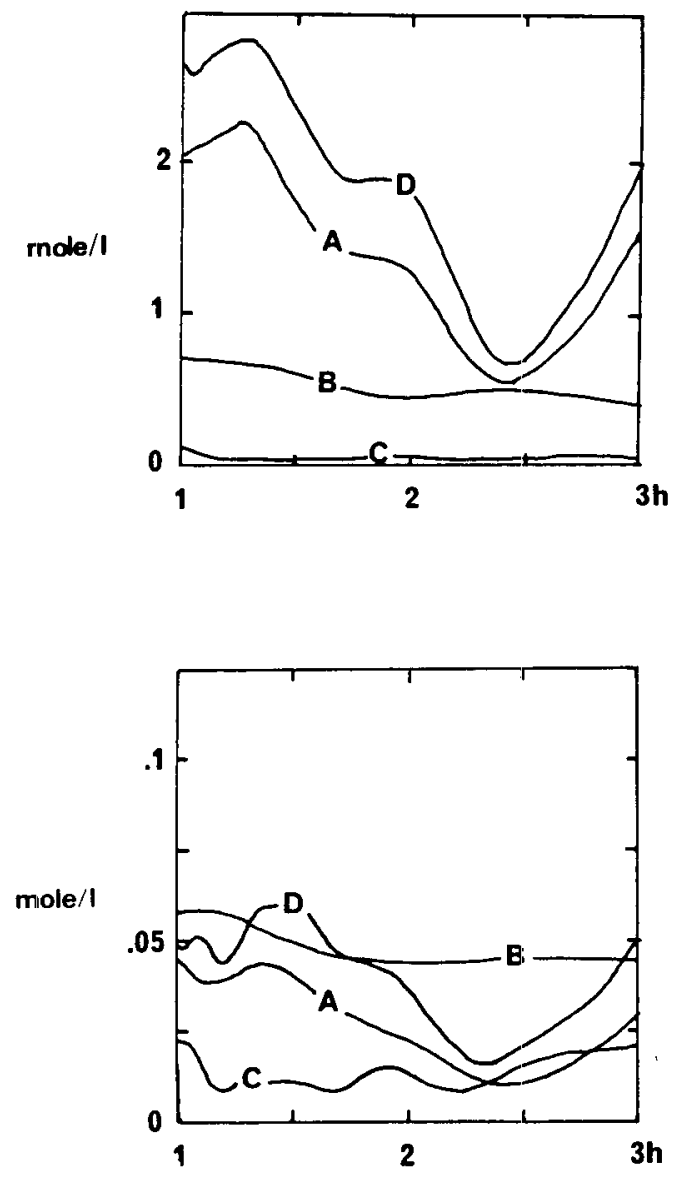

BERRY-REINHARDT
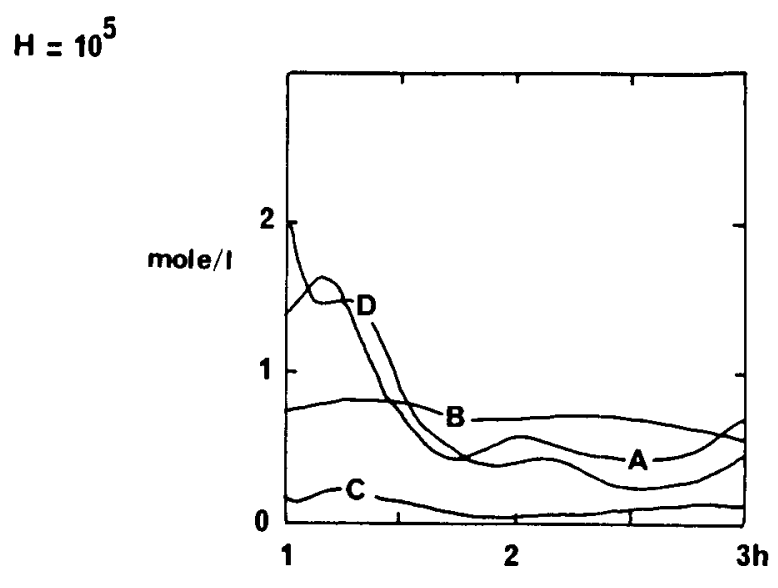

$H=10^{3}$

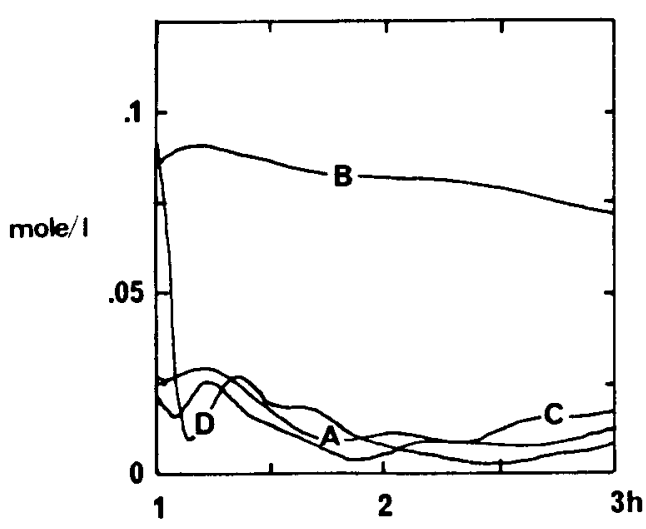

A.Microphysics B. Evaporation C.Scavenging D.Sedimentation

FIG. 6. Source and sink budgets over the entire model domain for rainborne species in the Kessler (1969) and Berry and Reinhardt $(1974 \mathrm{a}, \mathrm{b})$ cases as a function of time. Evolution over $2 \mathrm{~h}$ is presented for a highly soluble species and a less soluble one.

rainborne species is more efficient than in the Berry and Reinhardt case. Therefore, looking into more details, sedimentation is the most important process for the Kessler scheme and is rivaling microphysical and evaporation effects in the Berry and Reinhardt parameterization. For a less soluble species, evaporation is really the most important mechanism in the Berry and Reinhardt scheme and scavenging effects this time balance sedimentation and microphysical processes. In the Kessler case, sedimentation and evaporation are both dominating microphysical and scavenging processes. The importance of evaporation over the other processes is related to the previously mentioned concentration effect on the deposition rates (Fig. 5b). The evaporation effect is greater for the smaller raindrops represented in the Berry and Reinhardt parameterization. Conversely, sedimentation effects are larger in the Kessler case irrespective of the solubility because rainwater mass in that formulation is carried predominately by the larger raindrops.

\section{Conclusion}

A comparative study of two microphysical schemes corresponding to a mountain wave scenario was made to examine the impact of each of these schemes upon gas scavenging and wet deposition.

The Kessler scheme produces raindrop size spectra that are centered on larger diameters than that of the Berry and Reinhardt scheme. Consequently, there is a large discrepancy between the two schemes with respect 
to their treatment of direct gas scavenging by raindrops, which is a size-dependent process. Another effect related to drop size is the downwind spreading of the precipitating area, and subsequently of the deposition area. Deposition zones extend farther downwind from the mountain top in the case of Berry and Reinhardt. Furthermore, the smaller raindrops of the Berry and Reinhardt scheme are more efficient for absorbing gases and have longer residence times in the atmosphere, thereby providing more time for dissolving and scavenging the gases. Differences between the two schemes in the formulation of microphysical rates, such as the one for autoconversion, imply as well a different behavior for gas dissolution and scavenging. And finally, evaporation effects in the case of Berry and Reinhardt lead to an enhanced concentration of species on the downwind side relative to that obtained in the Kessler case, whereas sedimentation of large Kessler raindrops removes more gas from the air than is removed by the Berry and Reinhardt raindrops.

In conclusion, intricate chemical processes such as those involved in wet deposition evolve in a different manner in the Berry and Reinhardt scheme than in the Kessler scheme. An assessment of whether the Berry and Reinhardt scheme is more appropriate than that of Kessler must be determined by comparing model data and experimental data. However, it must also be noted that the Berry and Reinhardt scheme is computationally more expensive than the Kessler parameterization, and that for grid sizes larger than those considered in this paper, the Kessler scheme may be quite appropriate.

Acknowledgments. The authors wish to thank J. Duron for computing assistance. This work was supported by funds from ATP PIREN (CNRS), the French Ministry of Environment, and Electricité de France. Computer resources were provided by ECWMF (Reading, England), CCVR (Palaiseau, France, Project 1717), and Météorologie Nationale (Paris).

\section{REFERENCES}

Berry, E. X., and R. L. Reinhardt, 1973: Modeling of condensation and collection within clouds. Desert Res. Inst. Phys. Sci. Publ., 16.

tion: Part II. Single initial distributions. J. Atmos. Sci., 31, 18251831.

_ tion: Part III. Accretion and self-collection. J. Atmos. Sci, 31, 2118-2126.

Chaumerliac, N., E. Richard, J.-P. Pinty and E. C. Nickerson, 1987: Sulfur scavenging in a mesoscale model with quasi-spectral microphysics: two-dimensional results for continental and maritime clouds. J. Geophys. Res., 92, 3114-3126.

,-- and R. Rosset, 1989: Mesoscale modeling of acidity production in orographic clouds and rain, Atmos. Environ., 24A, 1573-1584.

Flossmann, A. I., and H. R. Pruppacher, 1988: A theoretical study of wet removal of atmospheric pollutants. Part III: The uptake, redistribution, and deposition of $\left(\mathrm{NH}_{4}\right)_{2} \mathrm{SO}_{4}$ particles by a convective cloud using a two-dimensional cloud dynamical model. J. Atmos. Sci., 45, 1857-1871.

Iribarne, J. V., and H. R. Cho, 1989: Models of cloud chemistry. Tellus, 41B, 2-23.

Kessler E., 1969: On the distribution and continuity of water substance in atmospheric circulations. Meteor. Monogr., 10, No. 32, Amer. Meteor. Soc., 84 pp.

Nickerson, E. C., E. Richard, R. Rosset and D. R. Smith, 1986: The numerical simulation of clouds, rain, and airflow over the Vosges and Black Forest Mountain: a meso- $\beta$ model with parameterized microphysics. Mon. Wea. Rev., 114, 398-414.

Niewiadomski, M., 1986: A passive pollutant in a three-dimensional field of convective clouds: numerical simulations. Atmos. Environ., 20, 139-146.

Noone, K. J., R. J. Charlson, D. S. Covert, J. A. Ogren and J. Heintzenberg, 1988: Cloud droplets: Solute concentration is size dependent. J. Geophys. Res., 93, 9477-9482.

Richard E., and N. Chaumerliac, 1989: Effects of different parameterizations on the simulation of mesoscale orographic precipitation. J. Appl. Meteor., 28, 1197-1212.

Rutledge, S. A., D. A. Hegg and P. V. Hobbs, 1986: A numerical model for sulfur and nitrogen scavenging in narrow cold-frontal rainbands, 2- Discussion of chemical fields. J. Geophys. Res., 91, 14 403-14 416.

Walcek, C. J., H. R. Pruppacher, J. H. Topalian and S. K. Mitra, 1984: On the scavenging of $\mathrm{SO}_{2}$ by clouds and raindrops: II. An experimental study of $\mathrm{SO}_{2}$ absorption and desorption for water drops in air. J. Atmos. Chem., 1, 291-306. 